\title{
The Effects of Some Processing Parameters on Physical and Densification Characteristics of Corncob Briquettes
}

\author{
J. T. Oladeji ${ }^{1, *}$ C. C. Enweremadu ${ }^{2}$ \\ ${ }^{1}$ Department of Mechanical Engineering Ladoke Akintola University of Technology, Ogbomoso, P. M.B. 4000, Nigeria \\ ${ }^{2}$ Department of Mechanical Engineering Vaal University of Technology, Private Bag X021, Vanderbijlpark 1900, South Africa
}

\begin{abstract}
Corncobs are generated from maize (Zea mays). The residue is usually dumped and flared on the farms, where it constitutes fire, environmental and health hazards. Corncobs are potential feedstock for energy generation. This work investigated densification characteristics of corncobs.

Corncobs were collected from farm dump at a moisture content of 10.96 dry bases, reduced and sieved into three particle sizes $\mathrm{S}_{1}, \mathrm{~S}_{2}$; and $\mathrm{S}_{3}$. Starch mutillage of 20,25 , and $30 \%$ by weight of the residue was added as binder. The briquettes were produced using briquetting machine at pressures of 2.1, 4.2 and 6.6 MPa. The ASAE standard methods were used to determine the moisture contents and densities of the milled residues and briquettes. The compaction, density and relaxation ratios as well as percentage expansion of the briquettes were determined using ASAE standard methods.

The mean moisture content of the corncob residue was $9.64 \%$, while that of relaxed briquettes was $7.46 \%$. The value of bulk densities of the residue materials was $50.32 \mathrm{~kg} / \mathrm{m} 3$. The initial, maximum and relaxed densities ranged from $151-235 \mathrm{~kg} / \mathrm{m} 3$; $533-981 \mathrm{~kg} / \mathrm{m} 3$ and $307-417 \mathrm{~kg} / \mathrm{m} 3$ respectively. The compaction ratio ranged from 2.27 to 6.50 . The maximum percentage volume reduction was $626 \%$, while the axial and lateral relaxations were in the range of $0.62-9.85 \%$ and $0.64-3.63$ respectively. The briquettes were stable up to six months. For the three processing parameters examined, binder ratio B1, particle size $\mathrm{S} 3$ and pressure $\mathrm{P} 3$ exhibited most positive attributes.
\end{abstract}

Keywords Briquettes, Binder Ratio, Compaction Pressure, Corncob. Particle Size, Residue

\section{Introduction}

Maize (Zea mays) ranks among the three major grain crops grown in Nigeria particularly the southern states of the country ([1]. About 5.3 million hectares of the crop are cultivated yearly[2]. According to Food and Agricultural Organization data[3], 589 million tons of maize was produced world-wide in the year 2005. The United States of America was the largest maize producer having $43 \%$ of world production. Africa produced $7 \%$ of the world's maize[4]. Nigeria was the second producer of maize in Africa in the year 2006 with 7.5 million tons[2]. In Nigeria alone, twenty eight different food items can be prepared from maize[5]. South Africa has the highest production of 11.04 million tons[4].

Corncob is the agricultural waste product obtained from maize or corn. Maize is mostly harvested and processed for food, leaving a large quantity of corncob residue constituting waste on the farm, most of which are flare off in preparation for subsequent farming season, thereby posing health risks to both human and ecology.

The corncob residue like any other organic wastes is

* Corresponding author:

jtoladeji@gmail.com (J. T. Oladeji)

Published online at http://journal.sapub.org/ijee

Copyright $(2012$ Scientific \& Academic Publishing. All Rights Reserved heterogeneous, varying in bulk density, moisture content, particle size and distribution depending on the mode of processing. Corncob is usually of low bulk density with high moisture content of up to $45 \%$ when harvested from the farm in partially dried form[6].

Many renowned researchers such as Grover and Mishra[7], Singh[8], Olorunnisola[9], Wilaipon[10], and Kaliyan and Morey[11], have worked on various aspects of briquetting, the nature of the materials during and after briquetting. The behaviour and characteristics of biomass briquetting can be classified into physical, mechanical and biochemical processes depending on the measured parameters. Therefore, the main aim of this work was to evaluate the effects of some processing parameters on physical and densification characteristics of briquettes produced from corncob.

\section{Materials and Methods}

Corncob residues were obtained from farm dumps and those that were healthy and fungus free were selected. They were sun-dried and their moisture content was determined using ASAE S269.4 2003[12]. The corncob residues were subjected to size reduction process through the use of hammer mill equipped with different screens in compliance with procedure described in ASAE 424.1 2003[13]. Three 
particle sizes $S_{1}(4.70 \mathrm{~mm}), S_{2}(2.40 \mathrm{~mm})$ and $S_{3}(0.60 \mathrm{~mm})$ representing coarse, medium and fine series respectively were selected. The bulk density of the unprocessed materials and relaxed briquettes were determined using ASAE standard. Starch mutillage (binder) was added to the residues at $20\left(\mathrm{~B}_{1}\right), 25\left(\mathrm{~B}_{2}\right)$, and $30 \%\left(\mathrm{~B}_{3}\right)$ by weight of the residue. A briquetting machine specially designed and fabricated for formation of briquettes was filled with a fixed charge of residue and compressed manually. Pressures of $2.40\left(\mathrm{P}_{1}\right)$, $4.40\left(\mathrm{P}_{2}\right)$ and $6.60\left(\mathrm{P}_{3}\right) \mathrm{MPa}$ were separately applied for each briquette formation. A dwell time of 120 seconds was observed for the briquettes during formation. The initial, maximum and the relaxed densities of the briquettes were determined using the mould dimension, the relaxed briquette's dimension and ASAE standard method of determining densities.

The compaction ratio was obtained from the relationship as expressed in equation (1)

$$
\text { Compaction Ratio }=\frac{\text { Maximum Density }}{\text { Initial Density }}
$$
2

The density ratio was calculated as expressed in equation

$$
\text { Density Ratio }=\frac{\text { Relaxed Density }}{\text { Maximum Density }}
$$

The relaxation ratio was obtained from the relationship in 3

$$
\text { Relaxation Ratio }=\frac{\text { Maximum Density }}{\text { Relaxed Density }}
$$

The briquette dimensions (length, breadth and height) in $\mathrm{cm}$ after extraction from the mould were measured.

The percentage volume reduction was calculated from equation 4

$$
=\frac{\begin{array}{c}
\% \text { Volume Reduction } \\
\text { Bulk Density of Relaxed briquettes }
\end{array}}{\text { Bulk Density of Unprocessed briquettes }}
$$

The percentage expansion was obtained from equation 5 as expressed by Mohsenin and Zaske, 1976.

$$
\% \text { Expansion }=\frac{I_{f-I_{i}}}{I_{i}} \times 100
$$

$I_{i}=$ initial height of briquettes, $I_{f}=$ final height of briquettes. The heights were measured with the aid of vernier callipers and micro meter screw gauge. Each measurement was replicated three times.

\section{Results and Discussions}

The sample contained $30.35 \%$ of particle size $4.70 \mathrm{~mm}$ $\left(\mathrm{S}_{1}\right), 20.10 \%$ of particle size $2.40 \mathrm{~mm}\left(\mathrm{~S}_{2}\right)$ and $13.8 \%$ of particle size $0.60 \mathrm{~mm}\left(\mathrm{~S}_{3}\right)$. The particle size analysis showed a preponderance of $S_{1}$ particle size over the other two particle sizes used in this work. The implication of this observation is that more materials will be required if particle size other than $\mathrm{S}_{1}$ is required for briquetting. However, the particle distribution would depend on the intensity of grinding.

The mean moisture content of the residue was $9.64 \%$ dry basis. This is within the acceptable operating moisture content of $8-12 \%$ for making briquetting $[7 ; 14 ; 15]$. However, the moisture content of some materials can be up to $20 \%$ and such materials can be densified in a piston press[11]. Moisture content above $10 \%$ might lead to excess steam production, which can lead to explosion as result of dissociation[16]. Besides, an increase in moisture content may not be favourable to the compaction process, as moisture may provide more resistance to formation of briquettes. Furthermore, moisture content in the range of $10 \%$ will result in denser, more stable and more durable briquette[16]. The moisture contents obtained in this work are safe for briquette production.

The mean bulk density of corncob residue and the relaxed briquettes were $50.32 \mathrm{~kg} / \mathrm{m}^{3}$ and $315.00 \mathrm{~kg} / \mathrm{m}^{3}$ respectively. This translates to percentage volume reduction of about 626 $\%$. The value of bulk density of raw corncob residue is higher than the minimum value of $40 \mathrm{~kg} / \mathrm{m}^{3}$ recommended by[11] for wooden materials, while the value of bulk density of relaxed briquettes obtained is desirable for group packaging and transportation of the briquettes, especially when compared with the initial bulk densities of untreated raw residues, which is $50.32 \mathrm{~kg} / \mathrm{m}^{3}$.

The density of the uncompressed mixture at different binder ratio and particle size varied from 151 to $235 \mathrm{~kg} / \mathrm{m}^{3}$ as shown in Table 1. The density of the uncompressed mixture increased with reduction in the particle size and increased with an increase in the binder ratio level. The implication of this is that the finer the particle, the less the pore spaces and more mass of the material per given volume which is good for briquetting. The effect of the particle size and binder ratio on the density of the uncompressed materials was significant $(\mathrm{p}<0.05)$.

Table 1. Initial Densities of Uncompressed Mixture at Different Binder Ratio and Particle Size for Corncob Residue (kg/m3)

\begin{tabular}{|c|c|c|c|}
\hline \multirow{2}{*}{$\begin{array}{c}\text { Binder Ratio } \\
\text { (\%) }\end{array}$} & \multicolumn{3}{|c|}{ Particle Size (mm) } \\
\cline { 2 - 4 } & S1 (4.70) & S2 (2.40) & S3 (0.60) \\
\hline B1 (20) & 151 & 185 & 218 \\
B2 (25) & 154 & 216 & 220 \\
B3 (30) & 157 & 233 & 235 \\
\hline
\end{tabular}

The maximum densities for the particle size S1, S2 and S3 varied from 533 to $981 \mathrm{~kg} / \mathrm{m} 3$ for briquettes as shown in Table 2. These values are higher than the initial densities of the uncompressed mixture of 151 to $235 \mathrm{~kg} / \mathrm{m} 3$. It was also observed that the higher the compaction pressure, the higher the density. From this result, it is evident that the briquetting process has been able to obtain increased density, which is a valuable factor in briquetting. The values of maximum densities obtained are more than the minimum value of 600 $\mathrm{kg} / \mathrm{m} 3$ recommended by $[15 ; 16]$ for efficient transportation and safe storage. An increase in the maximum density was observed at all particle sizes, as pressure increased. It was also observed that the maximum density decreased with increasing binder ratio.

As shown in Table 3, the relaxed densities of the briquettes varied from 314 t0 $420 \mathrm{~kg} / \mathrm{m}^{3}$.

These values are lower than 533 to $981 \mathrm{~kg} / \mathrm{m} 3$ obtained in this study for the maximum densities, but higher than the initial densities of 151 to $235 \mathrm{~kg} / \mathrm{m} 3$ for all particle sizes. The 
effects of pressure and percentage binder ratio by weight on maximum density for briquettes for the three particle sizes examined in this study are presented in Figures 1-3.

Table 2. Maximum Densities for Briquettes produced from Corncob $\left(\mathrm{kg} / \mathrm{m}^{3}\right)$

\begin{tabular}{|c|c|c|c|c|}
\hline \multirow{2}{*}{ Particle size } & Binder ratio & \multicolumn{3}{|c|}{ Compaction pressure (MPa) } \\
\cline { 3 - 5 } & $(\%)$ & P1(2.10) & P2(4.20) & P3(6.60) \\
\hline \multirow{3}{*}{ S1 (4.70 mm) } & B1 (20) & 750 & 802 & 981 \\
& B2 (25) & 636 & 692 & 802 \\
& B3 (30) & 554 & 570 & 624 \\
\hline \multirow{3}{*}{ S2 (2.40 mm) } & B1 (20) & 605 & 672 & 695 \\
& B2 (25) & 596 & 650 & 670 \\
& B3 (30) & 567 & 618 & 635 \\
\hline & B1 (20) & 600 & 643 & 678 \\
S3 (0.60 mm) & B2 (25) & 575 & 621 & 646 \\
& B3 (30) & 533 & 598 & 621 \\
\hline
\end{tabular}

Table 3. Relaxed Densities for Briquettes produced from Corncob $(\mathrm{kg} / \mathrm{m} 3)$

\begin{tabular}{|c|c|c|c|c|}
\hline \multirow{2}{*}{ Particle size } & Binder ratio & \multicolumn{3}{|c|}{ Compaction pressure (N/m2) } \\
\cline { 3 - 5 } & (\%) & P1(2.10) & P2(4.20) & P3(6.60) \\
\hline \multirow{3}{*}{ S1 (4.70 mm) } & B1 (20) & 314 & 346 & 352 \\
& B2 (25) & 332 & 337 & 348 \\
& B3 (30) & 307 & 314 & 335 \\
\hline \multirow{3}{*}{ S2 (2.40 mm) } & B1 (20) & 351 & 377 & 398 \\
& B2 (25) & 360 & 365 & 370 \\
& B3 (30) & 314 & 328 & 340 \\
\hline \multirow{3}{*}{ S3 (0.60 mm) } & B1 (20) & 390 & 397 & 405 \\
& B2 (25) & 412 & 420 & 417 \\
& B3 (30) & 404 & 405 & 410 \\
\hline
\end{tabular}

This is expected of the expansion in volume that takes place after extraction from the mould will increase the volume of the materials. The increase in volume with fixed mass will ultimately result in reduction in the density. A general trend of increase in the relaxed density was observed with increase pressure at different particle size. This could be due to the possible compactness of the material as pressure increases. An increase in the relaxed densities was observed generally as the binder level increases.

The compaction, density and relaxation ratios are shown in Tables 4, 5 and 6 respectively.

The results showed that compaction ratio varied from 2.27 to 6.50 for all pressures and binder ratios considered. Higher compaction ratio implied more void in the compressed materials. Higher figure indicates more volume displacement, which is good for packaging, storage and transportation and above all, it is an indication of good quality briquettes. From Table 4, it was observed that the compaction ratio increased with increasing pressure and decreased with increasing binder ratio. The implication of this is that, the void spaces are expelled at higher pressures, while less void spaces are present in the residue with higher quantity of binder ratio. Hence, it could be concluded that, there is more resistance to compression as the binder ratio increased. Furthermore, the values of compaction ratio obtained in this study compare and compete favourably well with notable biomass residues. For example, compaction ratio of 3.80 was obtained during briquetting of rice husk[17], while compaction ratios of 4.2 and 3.5 were obtained during briquetting of groundnut and melon shells respectively[18]. In the similar manner, compaction ratio of between 3.20 and 9.70 was obtained by Boluwafi[19] during briquetting of guinea corn residue.

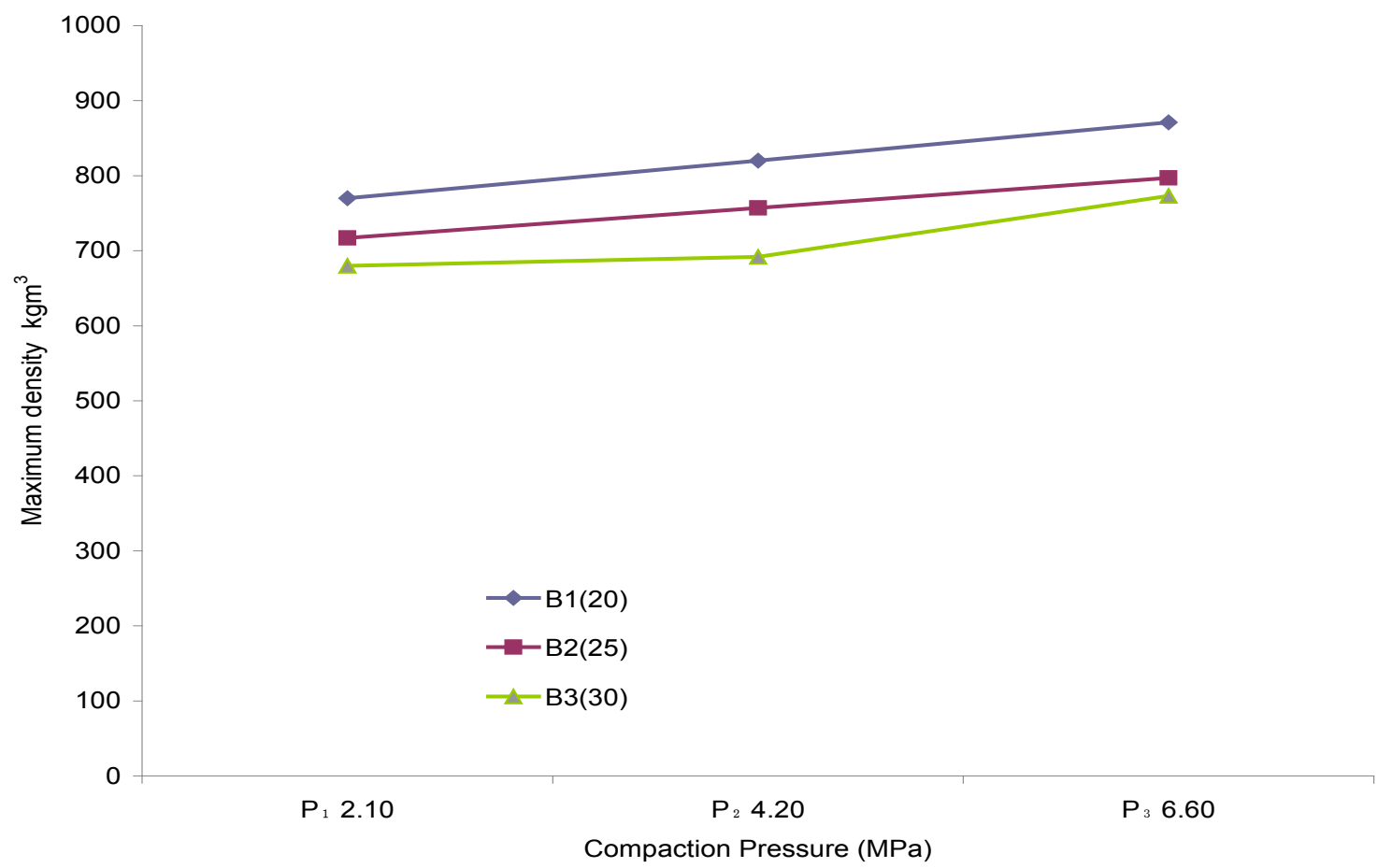

Figure 1. Effects of Pressure and Binder Ratio on Maximum Density for Briquettes for Particle Size $4.70 \mathrm{~mm}$ 


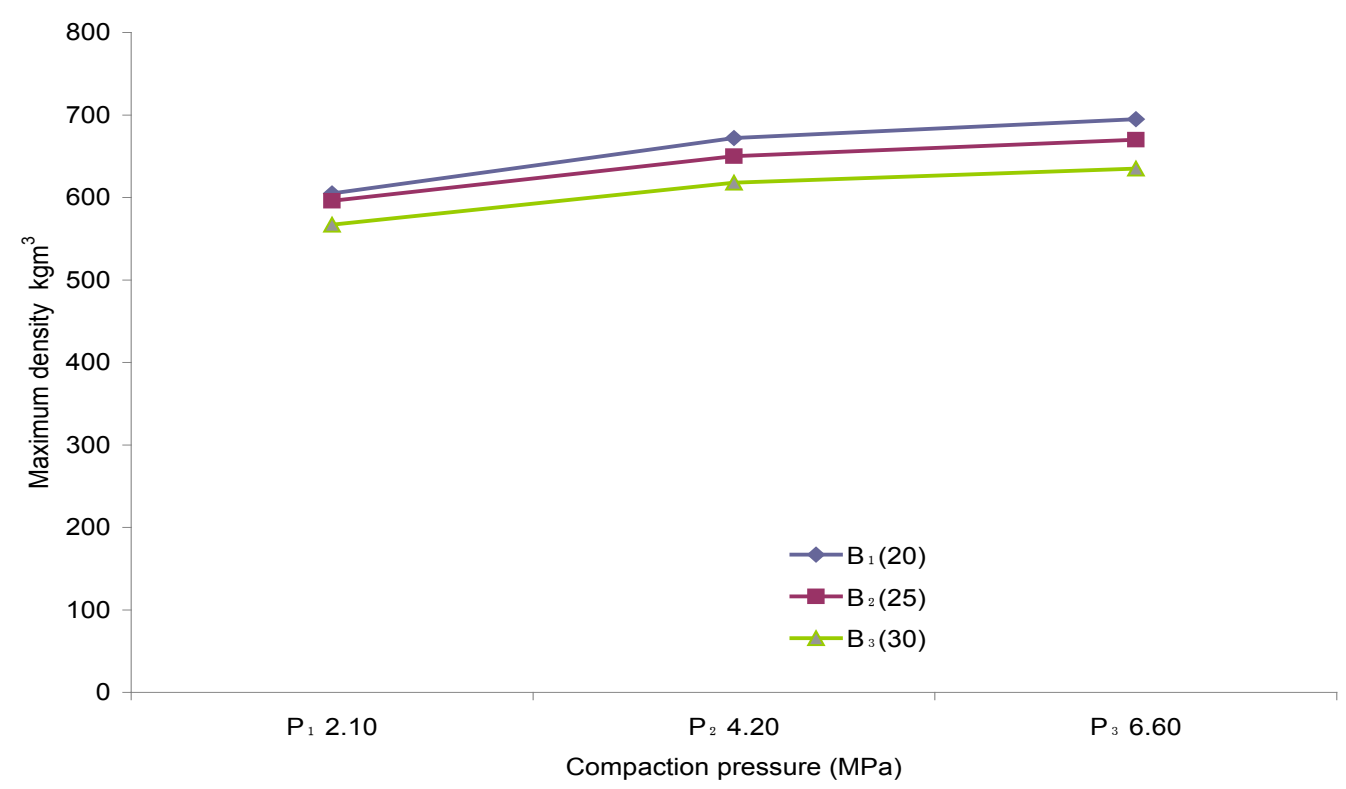

Figure 2. Effects of Pressure and Binder Ratio on Maximum Density for Briquettes from Corncob from white Maize for Particle Size $2.40 \mathrm{~mm}$

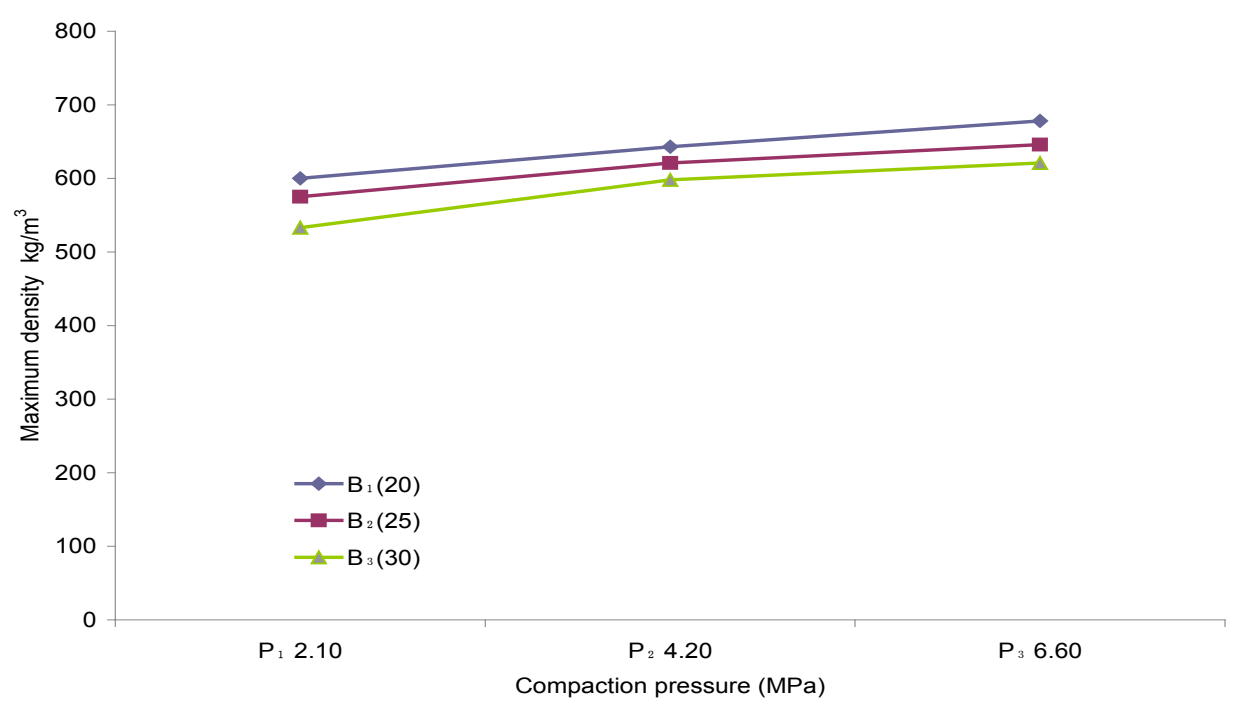

Figure 3. Effects of Pressure and Binder Ratio on Maximum Density for Briquettes for Particle Size $0.60 \mathrm{~mm}$

Table 4. Compaction Ratios for Briquettes produced from Corncob

\begin{tabular}{|c|c|c|c|c|}
\hline \multirow{2}{*}{ Particle size } & Binder ratio & \multicolumn{3}{|c|}{ Compaction pressure (N/m2) } \\
\cline { 3 - 5 } & $(\%)$ & P1(2.10) & P2(4.20) & P3(6.60) \\
\hline \multirow{3}{*}{ S1 (4.70 mm) $)$} & B1 (20) & 4.96 & 5.31 & 6.50 \\
& B2 (25) & 4.12 & 4.49 & 5.20 \\
& B3 (30) & 3.52 & 3.63 & 3.97 \\
\hline \multirow{3}{*}{ S2 (2.40 mm) } & B1 (20) & 3.27 & 3.63 & 3.75 \\
& B2 (25) & 2.76 & 3.01 & 3.10 \\
& B3 (30) & 2.43 & 2.65 & 2.72 \\
\hline \multirow{3}{*}{ S3 (0.60 mm) } & B1 (20) & 2.75 & 2.95 & 3.11 \\
& B2 (25) & 2.61 & 2.82 & 2.94 \\
& B3 (30) & 2.27 & 2.54 & 2.64 \\
\hline
\end{tabular}

The maximum and minimum values of density ratio for $\mathrm{S}_{1}$, $\mathrm{S}_{2}$, and $\mathrm{S}_{3}$ particle sizes are (0.55 and 0.35), (0.60 and 0.53) and ( 0.75 and 0.59$)$ respectively (Table 5$)$. The density ratios obtained in this work compared well with the results of Chin and Siddiqui[20], where values of density ratio of $0.07,0.71$, $0.2,0.41$ and 0.25 were recorded for rice husks, coconut fibres, sawdust, palm fibre and peanut shells respectively. Furthermore, a close study of the results revealed that the values of density ratio increased progressively with reducing particle size. The higher the value of the density ratio for a given mass, the less relaxed the briquettes are. Particle size $\mathrm{S}_{3}(0.60 \mathrm{~mm})$, which is the finest particle size exhibited the best result, as it relaxed less than the other two sizes after briquetting. The implication of this is that briquettes produced from particle size $S_{3}(0.60 \mathrm{~mm})$ are more stable than briquettes from other two sizes used in this study.

The maximum and minimum relaxation ratios of briquettes produced were found to be $2.86,1.82 ; 1.89,1.67$; and 
1.70, 1.33 for particle sizes $\mathrm{S}_{1}, \mathrm{~S}_{2}$ and $\mathrm{S}_{3}$ respectively (Table 6). These values compare favourably well and good enough as they are close to the values obtained by[9], which gave the relaxation ratio raging between 1.80 and 2.25 for coconut husk briquette and Oladeji et al.[18], which gave values 1.97 and 1.45 for groundnut and melon shell briquettes respectively. Furthermore, O'Dogherty[21] reported a comparable relaxation ratio in the range of 1.65 to 1.80 for briquetted hay materials, while Oladeji[22] obtained a relaxation ratio of 2.33 during the briquetting of rice husk. Lower value of relaxation ratio indicates a more stable briquette, while higher value indicates high tendency towards relaxation i.e. less stable briquette. The values of relaxation ratio obtained in this study indicated that briquettes from the finer particles are more stable than the coarse particles. A reciprocal relationship was observed between density ratio and relaxation ratio of the briquettes.

Table 5. Density Ratios for Briquettes produced from Corncob

\begin{tabular}{|c|c|c|c|c|}
\hline \multirow{2}{*}{ Particle size } & Binder ratio & \multicolumn{3}{|c|}{ Compaction pressure (N/m2) } \\
\cline { 3 - 5 } & $(\%)$ & P1(2.10) & P2(4.20) & P3(6.60) \\
\hline \multirow{3}{*}{ S1 (4.70 mm) } & B1 (20) & 0.42 & 0.43 & 0.35 \\
& B2 (25) & 0.52 & 0.48 & 0.43 \\
& B3 (30) & 0.55 & 0.55 & 0.53 \\
\hline \multirow{3}{*}{ S2 (2.40 mm) } & B1 (20) & 0.58 & 0.56 & 0.58 \\
& B2 (25) & 0.60 & 0.56 & 0.57 \\
& B3 (30) & 0.55 & 0.53 & 0.54 \\
\hline & B1 (20) & 0.65 & 0.62 & 0.59 \\
S3 (0.60 mm) & B2 (25) & 0.72 & 0.67 & 0.65 \\
& B3 (30) & 0.75 & 0.68 & 0.66 \\
\hline
\end{tabular}

Table 6. Relaxation Ratios for Briquettes produced from Corncob

\begin{tabular}{|c|c|c|c|c|}
\hline \multirow{2}{*}{ Particle size } & Binder ratio & \multicolumn{3}{|c|}{ Compaction pressure (MPa) } \\
\cline { 3 - 5 } & (\%) & P1(2.10) & P2(4.20) & P3(6.60) \\
\hline \multirow{3}{*}{ S1 (4.70mm) } & B1 (20) & 2.38 & 2.33 & 2.86 \\
& B2 (25) & 1.92 & 2.08 & 2.32 \\
& B3 (30) & 1.82 & 1.82 & 1.89 \\
\hline & B1 (20) & 1.72 & 1.78 & 1.72 \\
S2 (2.40 mm) & B2 (25) & 1.67 & 1.78 & 1.75 \\
& B3 (30) & 1.82 & 1.89 & 1.85 \\
\hline & B1 (20) & 1.54 & 1.61 & 1.70 \\
S3 (0.60 mm) & B2 (25) & 1.39 & 1.49 & 1.54 \\
& B3 (30) & 1.33 & 1.47 & 1.51 \\
\hline
\end{tabular}

The stability of briquettes produced from the two species examined in this study was determined in terms of dimensional expansion in the axial and lateral directions. Tables 7 and 8 showed dimensional change of briquettes in the axial and lateral directions.

Table 7. \% Axial Expansion for Briquettes produced from Corncob

\begin{tabular}{|c|c|c|c|c|}
\hline \multirow{2}{*}{ Particle size } & Binder ratio & \multicolumn{3}{|c|}{ Compaction pressure (MPa) } \\
\cline { 3 - 5 } & (\%) & P1(2.10) & P2(4.20) & P3(6.60) \\
\hline \multirow{3}{*}{ S1 (4.70 mm) $)$} & B1 (20) & 3.47 & 2.16 & 1.97 \\
& B2 (25) & 6.53 & 4.73 & 3.56 \\
& B3 (30) & 9.85 & 7.01 & 5.35 \\
\hline \multirow{4}{*}{ S2 (2.40 mm) } & B1 (20) & 2.53 & 1.07 & 0.98 \\
& B2 (25) & 4.36 & 2.56 & 1.75 \\
& B3 (30) & 6.11 & 4.15 & 2.63 \\
\hline \multirow{3}{*}{ S3 (0.60 mm) } & B1 (20) & 1.76 & 0.80 & 0.62 \\
& B2 (25) & 2.03 & 1.02 & 0.90 \\
& B3 (30) & 3.04 & 2.14 & 1.30 \\
\hline
\end{tabular}

From Tables 7 and 8 , it was observed that briquettes expanded largely in the axial direction than in the lateral direction. The change in briquette dimensions in the axial direction was up to $9.85 \%$ compared to maximum of $3.63 \%$ in the lateral direction. Similar expansion trend was also reported by Al-Widyan et al.[23] during briquetting of olive cake. The axial expansion of briquettes increased as the percentage binder ratio increased, which resulted in reduced relaxed density. However, the overall axial and lateral expansions reduced with an increase in pressure. Therefore, it was observed that percentage binder ratio had a significant effect on briquette stability. The briquettes from corncob showed no perceivable sign of disintegration after six months of storage.

Table 8. \% Lateral Expansion for Briquettes produced from Corncob

\begin{tabular}{|c|c|c|c|c|}
\hline \multirow{2}{*}{ Particle size } & Binder ratio & \multicolumn{3}{|c|}{ Compaction pressure (MPa) } \\
\cline { 3 - 5 } & $(\%)$ & P1(2.10) & P2(4.20) & P3(6.60) \\
\hline \multirow{3}{*}{ S1 (4.70 mm) } & B1 (20) & 1.40 & 0.92 & 0.64 \\
& B2 (25) & 2.04 & 1.36 & 0.96 \\
& B3 (30) & 3.63 & 2.58 & 1.76 \\
\hline \multirow{3}{*}{ S2 (2.40 mm) } & B1 (20) & 1.08 & 0.88 & 0.46 \\
& B2 (25) & 1.96 & 1.42 & 0.91 \\
& B3 (30) & 2.08 & 1.76 & 1.20 \\
\hline \multirow{3}{*}{ S3 (0.60 mm) } & B1 (20) & 0.98 & 0.72 & 0.48 \\
& B2 (25) & 1.24 & 1.02 & 0.83 \\
& B3 (30) & 1.76 & 0.94 & 0.65 \\
\hline
\end{tabular}

\section{Conclusions and Recommendations}

The present work examined the effects of processing parameters, specifically the effects of compaction pressure; \% binder ratio and particle size on physical and combustion characteristics of briquettes produced from corncobs. Based on the various results obtained and the findings of this study, the following conclusions have been made:

i. This study has found that, the handling (processing) parameters such as particle size, \% binder ratio and compaction pressure significantly affected the physical and densification characteristics of briquettes produced from corncob.

ii. Good quality and highly storable briquettes can be produced from the blend of corncob and cassava starch gel. This is because the briquettes produced have sufficient density and relaxed density. Furthermore, the shelf-life of the stored briquettes showed reasonable stability even after six months of storage.

iii. The bulk density of the relaxed briquettes, which is 315 $\mathrm{kg} / \mathrm{m}^{3}$ is higher than the residue materials, which is 50.32 $\mathrm{kg} / \mathrm{m}^{3}$. This translated into $626 \%$ volume reduction. It also provides technological benefits and a desirable situation for material storage, packaging and transportation.

iv. For all the three processing parameters examined in this study, variables with particle size $\mathrm{S} 3,(0.60 \mathrm{~mm})$, binder ratio B1 (20\%) and compaction pressure P3 (6.6 MPa) exhibited the most positive attributes than the other two variables. It can then be concluded that, the finer the particle size is, the more positive attributes of good quality briquette such 
particle has. In the similar manner, the lower the binder ratio, the better the briquettes, while higher compaction pressure will result in more quality briquettes.

\section{REFERENCES}

[1] Jekayinfa, S. O., and Scholz, V., 2009, "Potential Availability of Energetically Usable Crop Residues in Nigeria" Energy Sources, Part A, Vol. 31: 687-697

[2] FOS, 2006, Federal Office of Statistics, Agricultural Survey, 2003/04, Federal Ministry of Agriculture (June, 2006)

[3] FAO, 2007, Agricultural Database. Available from http:/www.fao.org (accessed on June, 24, 2007)

[4] Adesanya, D. A., and Raheem, A. A., 2009, "A study of the workability and compressive strength characteristics of corn cob ash blended cement concrete" Construction and Building Materials 23: 311-317

[5] BCOS, 2010. Uses of Corn- A Broadcasting Corporation of Oyo State Programme "Magazine" aired on $14^{\text {th }}$ September, 2010

[6] Oladeji, J.T., 2011, "The Effects of Some Processing Parameters on Physical and Combustion Characteristics of Corncob Briquettes" An Unpublished Ph.D Thesis of the Department of Mechanical Engineering, Ladoke Akintola University of Technology, Ogbomoso, Nigeria

[7] Grover, P.D., and Mishra, S. K., 1996, "Biomass Briquetting, Technology and Practices", Regional Wood Energy Development Programme in Asia, Field document No. 46 Bangkok, Thailand; FAO

[8] Singh, R.N., Bhoi, P.R. and Patel, S.R., 2007 "Modification of commercial briquetting machine to produce $35 \mathrm{~mm}$ diameter briquettes suitable for gasification and combustion" Renewable Energy, Vol. 32 No. 3 pp 474-479

[9] Olorunnisola, A. O., 2007, "Production of Fuel Briquettes from Waste Paper and Coconut Husk Admixture" Agricultural Engineering International: the CIGR E-journal. Manuscript EE 06006 Vol. IX

[10] Wilaipon, P., 2009, "Density Equation of Bio-Coal Briquettes and Quantity of Maize cob in Phitsanulok, Thailand" American Journal of Applied Sciences 5 (12):1808-1811

[11] Kaliyan, N., and Morey, R. V., 2009, "Factors affecting strength and durability of densified biomass products" Biomass and Bioenergy 33, 337-359

[12] ASAE, S269.4. 2003, - Cubes, pellets and crumbles - definitions and methods for determining density, durability and moisture content. 567 - 569. St. Joseph, Mich.: U.S.A

[13] ASAE S 424.1., 2003, Method of determining and expressing particles size of chopped forage materials by screening 606-608, St. Joseph, Michigan

[14] Wilaipon, P., 2008, "The Effect of Briquetting Pressure on Banana-Peel Briquette and the Banana Waste in Northern Thailand". American Journal of Applied Sciences 6(1): 167-171

[15] Gilbert, P., Ryu, C., Sharif, V., and Switchenbank, J., 2009, "Effect of processing parameters on pelletisation of herbaceous crops" Fuel 88:1491-1497

[16] Mani, S., Tabil, L.G., and Sokhansanj, S., 2006, "Specific energy requirement for compacting corn stover" Bioresource Technology 97 1420-1426

[17] Oladeji, J.T., 2010a "Fuel Characterization of Briquettes Produced from Corncob and Rice Husk Residues". Pacific Journal of Science and Technology 11(1):101-106

[18] Oladeji, J. T., Enweremadu, C.C., and Olafimihan, E. O., 2009, "Conversion of Agricultural Wastes into Biomass Briquettes" IJAAAR 5 (2): 116-123

[19] Bolufawi, S.J., 2011, "Briquetting Characteristics in Relation to Fuel Values of Guinea Corn (Sorghum bicolor) Residue" An Unpublished Ph.D Thesis of the Department of Agricultural and Environmental Engineering, University of Ibadan, Nigeria

[20] Chin, O. C., and Siddiqui, K. M., 2000, "Characteristics of some biomass briquettes prepared under modest die pressures" Biomass and Bioenergy, 18:223-228

[21] O’Dogherty, M. J., 1989, “A review of mechanical behaviour of straw when compressed to high densities" Journal of Agricultural Engineering Research 44: 241-265

[22] Oladeji, J.T., 2010b "Pyrolytic Conversion of Sawdust and Rice Husk to Medium Grade Fuel". Proceedings of 2010 Conference of the Nigerian Institute of Industrial Engineers (NIIE 2010), Ibadan, April 22-24, pp. 81-86

[23] Al-Widyan, M. I., Al-Jalil, H. F., Abu-Zreig, M. M., and Abu-Hamdey, N. H., 2002, "Physical Durability and Stability of Olive Cake Briquettes" Canadian Bio systems Engineering, Vol.44, No, 3 pp 41-45 